\title{
An overview of the European Society of Medical Oncology (ESMO) Symposium on Cancer and Nutrition 2009: from cancer prevention to nutrition support to alleviating suffering in patients with advanced cancer
}

\author{
Florian Strasser • An Van den Broek • Aminah Jatoi
}

Received: 6 April 2011 /Accepted: 31 July 2011 /Published online: 1 September 2011

(C) Springer-Verlag 2011

\section{Introduction}

The European Society of Medical Oncology Symposium (ESMO) on Cancer and Nutrition convened on March 2021, 2009, in Zurich, Switzerland. Welcoming 172 participants from 32 countries and from 4 different continents, this symposium was designed to address issues directly relevant to the interface between clinical nutrition and cancer. Was there truly a need for such a conference? The organizers of this meeting contend that the answer is "yes" and cite the following salient examples to show that nutrition really does impact cancer and cancer patients and that focusing a symposium on the interface between nutrition and cancer holds merit.

\section{F. Strasser $(\square)$}

Oncological Palliative Medicine, Division

of Oncology/Haematology, Department of Internal Medicine and Palliative Care Center, Cantonal Hospital,

Rorschacherstrasse 95,

CH-9007 St. Gallen, Switzerland

e-mail: florian.strasser@kssg.ch

\section{A. Van den Broek}

Department of Medical Oncology, Ziekenhuisnetwerk

Antwerpen-Middelheim,

Antwerp, Belgium

\section{A. Jatoi}

Division of Medical Oncology, Mayo Clinic,

Rochester, MN, USA

\section{A. Jatoi $(\bowtie)$}

Mayo Clinic,

200 First Street SW,

Rochester, MN, USA 55905

e-mail: jatoi.aminah@mayo.edu
Firstly, it behooves us to always test assumptions of efficacy and safety, particularly with nutritional interventions which are often assumed to be safe. Rates of vitamin/ nutritional supplementation vary dramatically throughout the world, but, in some populations, as many as $80 \%$ of individuals are taking them $[15,27]$. Despite this high prevalence, only a few studies have demonstrated that supplements prevent cancer, and such studies suggest benefits are confined to nutrient-depleted populations [17]. For example, when one considers the plethora of epidemiologic data that points to an association between beta carotene-rich fruits and vegetables and a diminished risk of lung cancer, it is tempting to conclude-albeit prematurely and unwisely - that beta carotene supplementation is safe and even beneficial. Subsequent studies have nullified this conclusion. In the recent VITAL study that included 77,126 individuals, Satia and others reported that long-term use of patient-reported beta carotene ( $<10$ years) was associated with a greater risk of lung cancer [21]. More importantly, two placebo-controlled, double-blinded randomized clinical trials tested $\beta$-carotene at doses of $30 \mathrm{mg}$ in 18,314 individuals and $20 \mathrm{mg}$ in 29,133 individuals all of whom were at high risk for lung cancer. Unexpectedly, both these trials demonstrated that the incidence of lung cancer increased by $28 \%$ or more and that, as a result, mortality was worse as a result of beta carotene supplementation. Yes, the unthinkable can happen, and therefore, rigorous testing with proof of safety and efficacy must be established prior to recommending any nutritional supplements, particularly those prescribed at "high" doses.

Secondly, one might question whether diet itself has any favorable effect on cancer or cancer recurrence. The Women's Intervention Nutrition Study suggests that it does. A total of 2,437 early-stage breast cancer patients were 
randomly assigned to one of two arms: a diet that consisted of a $20 \%$ reduction in fat versus a regular diet. Preliminarily, relapse-free survival was more favorable in the intervention arm that received the $20 \%$ reduction in fat intake; the hazard ratio on the intervention arm was 0.76 (95\% confidence intervals $0.60,0.98 ; p=0.77$ for stratified $\log$ rank and $p=0.034$ for adjusted Cox model analysis). Did this difference in relapse-free survival occur by chance? Did the weight loss that occurred from a low fat diet contribute to this favorable outcome? Or did other healthpromoting habits that may have occurred with the dietary intervention lead to these improved outcomes? Although this study prompted many more questions than it answered, the tentative observation that a modification in diet can affect cancer outcomes should be carefully noted. This study underscores the importance of conducting dietary research in cancer patients and cancer survivors and suggests that diet can truly make a difference in cancer outcomes.

Thirdly, nutritional counseling has always been an important aspect of cancer care, but recent data have refocused attention on this intervention. At the symposium, it was discussed that intensive dietary counseling has grade " $A$ " evidence in favor of its use to prevent weight loss and treatment interruptions in patients with gastrointestinal and head and neck malignancies [20]. Ravasco also presented data on the late effects of radiotherapy, showing improvement of diarrhea, abdominal distention, and flatulence in the nutrition intervention group (group 1) compared to the less-intensive counseling groups (group 2, nutritional supplements; group 3, control) and even more astonishingly showed a $100 \%$ survival in group 1 in contrast to groups 2 and 3 which had a 4 -year survival of $88 \%$ versus $75 \%$. It can be summarized that there is good evidence that individualized nutritional counseling improves outcomes. Professor Laviano discussed that malnutrition is a risk factor for decreased survival and post-operative complications [3, 14, 19, 23]. Despite this risk, few interventionswith few exceptions such as that described by Ravascohave been able to improve such poor outcomes [22].

Fourthly, given the importance of malnutrition as a risk factor for decreased anticancer treatment tolerance and poor survival, the importance of early detection of nutritional risk and malnutrition was discussed. A variety of clinically feasible screening tools are available in daily practice. Zeno Stanga summarized simple screening tools for the community (MUST), hospital (NRS 2002), and geriatric care homes (MNA), all with moderate to substantial inter-rater reliability. Several abstracts documented the impact of systematic nutritional assessment (and counseling) on cancer relevant outcomes. For example, Rüfenacht et al. presented findings from a randomized controlled trial in an oncology outpatient setting, comparing nutritional counsel- ing and oral nutrition supplementation versus a less aggressive approach. Preliminary results of 14 patients suggested improved energy intake and quality of life with the former. A study by Sharma et al. suggested that a comprehensive symptom control and pain management program that included enteral nutrition support can lead to improved nutritional status and higher completion rates of palliative anticancer therapy.

Fifthly, some of the potentially detrimental effects of nutritionally based therapies were also discussed. Two presentations by Vandebroek and Jatoi summarized the current knowledge of nutritional or herbal supplements and anticancer drugs with an emphasis on oral anticancer treatments. A key point of Vandebroek was that $38-85 \%$ of patients taking herbs or nutritional supplements (including antioxidants, vitamins, etc.) are in a "communication disconnect": they have no consultation with the physician emphasizing these issues. This contrasts to the manifold potential interactions on pharmacokinetics (absorption, distribution, metabolism, elimination) and pharmacodynamics. Red flag substances encompass not only grape fruit, St. John's Worth, ginkgo, ginseng, echinacea, kava, grape seed, and evening primrose but also substances causing excess and depletion of antioxidants. These data demonstrate that nutrition is important to patients to fight cancer, but oncologists need to "be aware" and seek actively communication about eating habits.

As sixth example of the importance of nutrition and cancer, at the symposium, the management of patients with advanced, incurable cancer was discussed. Alessandro Laviano emphasized the various effects of anticancer treatment: (1) that tumor response is often associated with improvement of cachexia-related symptoms [8, 12], (2) that anticancer treatment can deteriorate energy intake [16, 24], and (3) that chemotherapeutic agents can directly affect skeletal muscle [25]. These data suggest that continuous monitoring of patients' nutritional intake [4], weight, and associated symptoms (e.g., early satiety, fatigue) is of value. A recent paper by Deans investigating various cytokine polymorphisms in patients with gastroesophageal malignancies demonstrated that the IL10-1082 gene promoter polymorphism is associated with increased total weight loss, but-at diagnosis - not the interleukin-6 polymorphism (IL6-174). Patients carrying the interleukin10 GG allele have a 2.3-fold increased risk to develop cachexia [6]. The developing cancer cachexia classification no longer focuses on weight loss and anorexia only but includes key domains (anorexia/reduced food intake, catabolic drive/inflammation, loss of muscle mass and strength, additional metabolic and endocrine factors, impact of cachexia, physical and psychological functioning). Strasser summarized the international work on a generic cachexia definition [7] and the cancer-specific classification 
work led by the European Palliative Care Research Collaborative [11]. In line with this multidomain understanding of cancer cachexia, several groups pursue a multitarget anti-cachexia treatment, both in animals [26] and cancer patients [13]. Orrevall presented in a very recent paper [18], based on 21 palliative home care services and telephone interviews with 621 patients, a high frequency of not only combined oral nutrition and oral supplements (41\%) but also artificial nutrition (14\%). Accompanying qualitative interviews from a prior study demonstrate that patients and family members seem to have physical, social, and psychological benefits from home nutritional support, even in a life span of a couple of months. Since a majority of patients with advanced cancer raised concerns about weight loss or eating less [9], interventions were developed based on education and communication, conflict management, and empowerment of the patient to support eating well and self action. This McMillan approach to weight loss and eating difficulties was tested in a two-site clusterrandomized controlled trial, investigating the effectiveness of this approach.

\section{The ESMO Symposium on Cancer and Nutrition: spectrum of topics and concluding messages}

Studies such as those alluded to above as well as others demonstrate that the study of nutrition and cancer is ripe with promise. Thus, the ESMO Symposium on Cancer and Nutrition was organized and convened to provide a state-ofthe art discussion of these subjects. It is important to emphasize that the topics included those mentioned above, representing a spectrum of interests from (1) the impact of nutrition on cancer prevention and survivorship, (2) the evaluation of the nutritional status of the cancer patient, (3) the use of nutrition to improve patient outcomes, (4) interactions between nutritional interventions and patient outcomes, and (5) a discussion of nutritional issues in patients with advanced cancer. In total, 29 oral presentations as well as numerous poster-based abstracts were included within this symposium, which provided both an update of previously reported data as well as observations that had never before been presented.

In the symposium's concluding remarks, two important recommendations emerged. First, the multidisciplinary aspect of this symposium - with the inclusion of epidemiologists, basic scientists, nutritionists, psychologists, primary care physicians, and oncologists-suggested the importance of recognizing nutrition-related guidelines already formulated by a host of other prominent organizations, such as the European Society of Parenteral and Enteral Nutrition, the American Society of Parenteral and Enteral Nutrition, the American Cancer Society as well as others [1, 2, 5, 10]. Second, the value of and lack of precedent for such a symposium were such that the possibility of making nutrition and cancer a recurring theme for future symposia was duly noted and encouraged. The value of focusing on the interface between nutrition and cancer should be recognized as future symposia are planned.

Conflicts of interest The authors have no conflicts of interest in relation to the content of this editorial.

\section{References}

1. ACS webpage: http://www.cancer.org/acs/groups/cid/documents/ webcontent/002577-pdf.pdf (last accessed June 2011)

2. August DA, Huhmann MB (2009) A.S.P.E.N. clinical guidelines: nutrition support therapy during adult anticancer treatment and in hematopoietic cell transplantation. JPEN J Parenter Enteral Nutr 33(5):472-500

3. Bachmann J, Heiligensetzer M, Krakowski-Roosen H, Büchler MW, Friess H, Martignoni ME (2008) Cachexia worsens prognosis in patients with resectable pancreatic cancer. J Gastrointest Surg 12(7):1193-1201

4. Blum D, Oberholzer R, Linder S, Hess J, Omlin A, Jurt G, Strasser F (2009) Secondary nutrition impact symptoms: predictors of nutritional intake response to comprehensive nutritional counseling in advanced cancer patients. ESMO Symposium Nutrition and Cancer; Abstract 10PD

5. Bozzetti F, Arends J, Lundholm K, Micklewright A, Zurcher G, Muscaritoli M, ESPEN (2009) ESPEN guidelines on parenteral nutrition: non-surgical oncology. Clin Nutr 28(4):445-454

6. Deans DA, Tan BH, Ross JA, Rose-Zerilli M, Wigmore SJ, Howell WM, Grimble RF, Fearon KC (2009) Cancer cachexia is associated with the IL10-1082 gene promoter polymorphism in patients with gastroesophageal malignancy. Am J Clin Nutr 89 (4):1164-1172

7. Evans WJ, Morley JE, Argilés J, Bales C, Baracos V, Guttridge D, Jatoi A, Kalantar-Zadeh K, Lochs H, Mantovani G, Marks D, Mitch WE, Muscaritoli M, Najand A, Ponikowski P, Rossi Fanelli F, Schambelan M, Schols A, Schuster M, Thomas D, Wolfe R, Anker SD (2008) Cachexia: a new definition. Clin Nutr 27 (6):793-799

8. Geels P, Eisenhauer E, Bezjak A, Zee B, Day A (2000) Palliative effect of chemotherapy: objective tumor response is associated with symptom improvement in patients with metastatic breast cancer. J Clin Oncol 18(12):2395-2405

9. Hopkinson JB, Wright DN, McDonald JW, Corner JL (2006) The prevalence of concern about weight loss and change in eating habits in people with advanced cancer. J Pain Symptom Manage 32(4):322-331

10. Huhmann MB, August DA (2008) Review of American Society for Parenteral and Enteral Nutrition (ASPEN) clinical guidelines for nutrition support in cancer patients: nutrition screening and assessment. Nutr Clin Pract 23(2):182-188

11. Kaasa S, Loge JH, Fayers P, Caraceni A, Strasser F, Hjermstad MJ, Higginson I, Radbruch L, Haugen DF (2008) Symptom assessment in palliative care: a need for international collaboration. J Clin Oncol 26(23):3867-3873

12. Koeberle D, Saletti P, Borner M, Gerber D, Dietrich D, Caspar CB, Mingrone W, Beretta K, Strasser F, Ruhstaller T, Mora O, 
Herrmann R, Swiss Group for Clinical Cancer Research (2008) Patient-reported outcomes of patients with advanced biliary tract cancers receiving gemcitabine plus capecitabine: a multicenter, phase II trial of the Swiss Group for Clinical Cancer Research. J Clin Oncol 26(22):3702-3708

13. Mantovani G, Madeddu C, Gramignano G, Serpe R, Massa E, Deiana L, Macciò A (2007) An innovative treatment approach for cancer-related anorexia/cachexia and oxidative stress: background and design of an ongoing, phase III, randomized clinical trial. Support Cancer Ther 4(3):163-167

14. Meyerhardt JA, Tepper JE, Niedzwiecki D, Hollis DR, McCollum AD, Brady D, O’Connell MJ, Mayer RJ, Cummings B, Willett C, Macdonald JS, Benson AB 3rd, Fuchs CS (2004) Impact of body mass index on outcomes and treatment-related toxicity in patients with stage II and III rectal cancer: findings from Intergroup Trial 0114. J Clin Oncol 22(4):648-657

15. Miller P, Demark-Wahnefried W, Snyder DC, Sloane R, Morey MC, Cohen H, Kranz S, Mitchell DC, Hartman TJ (2006) Dietary supplement use among elderly, long-term cancer survivors. J Cancer Surviv 2(3):138-148

16. Ohno T, Kato S, Wakatsuki M, Noda SE, Murakami C, Nakamura M, Tsujii H (2006) Incidence and temporal pattern of anorexia, diarrhea, weight loss, and leukopenia in patients with cervical cancer treated with concurrent radiation therapy and weekly cisplatin: comparison with radiation therapy alone. Gynecol Oncol 103(1):94-99

17. Omenn GS, Goodman GE, Thornquist MD, Balmes J, Cullen MR, Glass A, Keogh JP, Meyskens FL, Valanis B, Williams JH, Barnhart S, Hammar S (1996) Effects of a combination of beta carotene and vitamin A on lung cancer and cardiovascular disease. N Engl J Med 334(18):1150-1155

18. Orrevall Y, Tishelman C, Permert J, Cederholm T (2009) Nutritional support and risk status among cancer patients in palliative home care services. Support Care Cancer 17(2):153-161
19. Pacelli F, Bossola M, Rosa F, Tortorelli AP, Papa V, Doglietto GB (2008) Is malnutrition still a risk factor of postoperative complications in gastric cancer surgery? Clin Nutr 27(3):398-407

20. Ravasco P, Monteiro Grillo I, Camilo M (2007) Cancer wasting and quality of life react to early individualized nutritional counselling! Clin Nutr 26(1):7-15

21. Satia JA, Littman A, Slatore CG, Galanko JA, White E (2009) Long-term use of beta-carotene, retinol, lycopene, and lutein supplements and lung cancer risk: results from the VITamins And Lifestyle (VITAL) study. Am J Epidemiol 169(7):815-828

22. Sharma R, Singh DP, Sharma OP, Sharma S (2009) Improvement of nutritional status in advanced head and neck cancer patients. ESMO Symposium Nutrition and Cancer; Abstract 17PD

23. Tewari N, Martin-Ucar AE, Black E, Beggs L, Beggs FD, Duffy JP, Morgan WE (2007) Nutritional status affects long term survival after lobectomy for lung cancer. Lung Cancer 57(3):389-394

24. van den Berg MG, Rasmussen-Conrad EL, Gwasara GM, Krabbe PF, Naber AH, Merkx MA (2006) A prospective study on weight loss and energy intake in patients with head and neck cancer, during diagnosis, treatment and revalidation. Clin Nutr 25(5):765772

25. van Norren $\mathrm{K}$, van Helvoort A, Argilés JM, van Tuijl S, Arts K, Gorselink M, Laviano A, Kegler D, Haagsman HP, van der Beek EM (2009) Direct effects of doxorubicin on skeletal muscle contribute to fatigue. Br J Cancer 100(2):311-314

26. van Norren K, Kegler D, Argilés JM, Luiking Y, Gorselink M, Laviano A, Arts K, Faber J, Jansen H, van der Beek EM, van Helvoort A (2009) Dietary supplementation with a specific combination of high protein, leucine, and fish oil improves muscle function and daily activity in tumour-bearing cachectic mice. Br J Cancer 100(5):713-722

27. Velicer CM, Ulrich CM (2008) Vitamin and mineral supplement use among US adults after cancer diagnosis: a systematic review. J Clin Oncol 26(4):665-673 